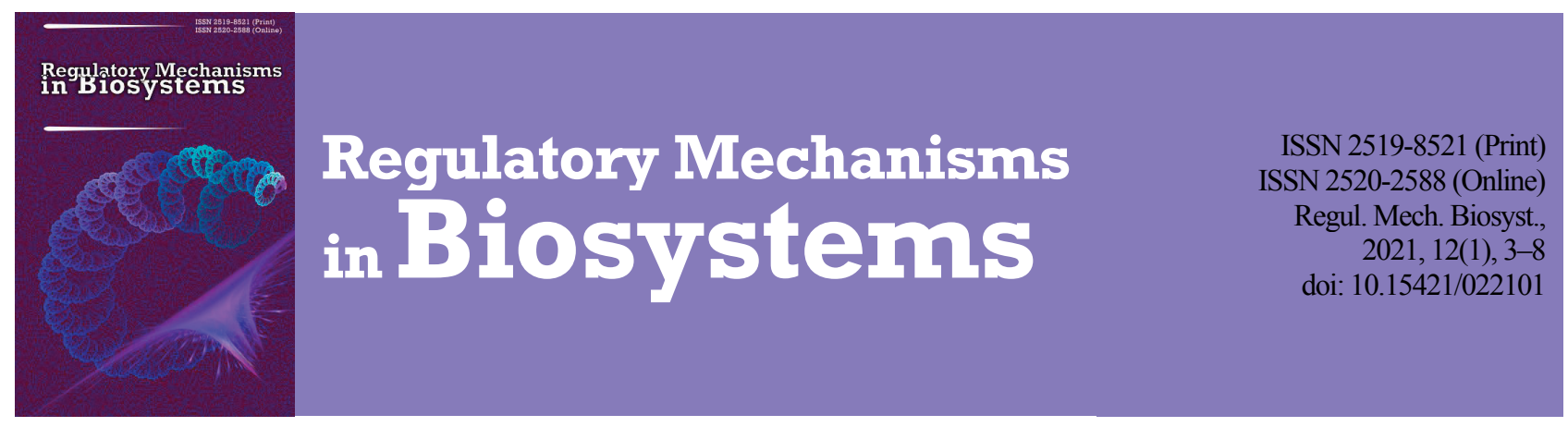

\title{
Microstructure of the nerve plexus of the muscular membrane of the gut of domestic ducks (Anas platyrhynchos domesticus) of different ages
}

\author{
M. M. Kushch, D. S. Makhotyna, I. A. Fesenko, M. M. Savenko, A. Y. Ulianytska \\ Kharkiv State Zooveterinary Academy, Mala Danylivka, Ukraine
}

Article info

Received 11.01.2021

Received in revised form 14.02.2021

Accepted 15.02.2021

Kharkiv State

Zooveterinary Academ Akademichna st., 1 ,

Mala Danylivka, 62341

Derhachivskyi District,

Kharkiv Oblast, Ukraine.

Tel.: +38-057-63-57-480

E-mail:

dr.kushch@meta.ua

\begin{abstract}
Kushch, M. M., Makhotyna, D. S., Fesenko, I. A., Savenko, M. M., \& Ulianytska, A. Y. (2021). Microstructure of the nerve plexus of the muscular membrane of the gut of domestic ducks (Anas platyrhynchos domesticus) of different ages. Regulatory Mechanisms in Biosystems, 12(1), 3-8. doi:10.15421/022101
\end{abstract}

As evidenced by the publications of recent years, contrary to the existing dogma about the immutability of the state of the enteric nervous system during the postnatal period of ontogenesis, the population of intestinal neurons is a dynamic formation, decreasing with age and changing due to the action of environmental factors. The current article presents the results of study of the microscopic structure of the nerve plexus of the muscular membrane of the enteric nervous system of domestic ducks (Anas platyrhynchos domesticus) of the black white-breasted breed, of nine age groups of 1-365 days of age. The topography, number, area of nerve nodes, as well as the density of neurons in them were determined on transverse sections of the duodenum, jejunum, ileum, caecum and rectum. For the purpose of a generalized assessment of the morphofunctional state of the nerve plexuses, two parameters were determined: the average age indicator of the gut and intestines. The average age indicator of a certain structure of each intestine was determined as the arithmetical average of its nine age indicators. The average age indicator of a certain gut structure was determined as the arithmetic average of the average age indicator of the structure of all five intestines. It has been established that the nerve plexus of the muscular membrane (myenteric, plexus Auerbachi) of the gut of domestic ducks, in contrast to mammals, is not located between the layers of the muscular membrane, but in its outer layer. On a transverse section of the gut wall, the myenteric ganglia and cords that connect have a predominantly elliptical shape. Despite a significant increase with age in the diameter and thickness of the gut wall, the total number of myenteric ganglia changed little, increasing or decreasing with varying degrees of reliability relative to the previous age. In the gut of ducks, during the first year of the postnatal period of ontogenesis, the smallest number of myenteric ganglia was found in the cecum, and the largest - in the ileum. The general pattern of the dynamics of the size of the myenteric ganglia of the gut of ducks was an increase in their area with age. Moreover, this indicator reached the greatest value at different ages of ducks: at 30 days of age in the ileum and cecum, at 180 days of age - in the rectum and at 365 days of age - in the duodenum. The smallest area of the myenteric ganglia was found in the jejunum, and the largest - in the duodenum and ileum. The smallest number of neurons in the ganglion was found in the cecum, and the largest - in the rectum, the lowest density of neurons in the ganglion was found in the cecum, and the largest - in the jejunum. The general quantitative pattern of neurons in the ganglion was the decrease in their density with age. Changes in the morphometric parameters of the ganglia of the nerve plexus of the muscular membrane of the ducks' gut indicate the plasticity of the enteric nervous system, its ability to dynamically respond to the action of factors of the internal and external environment. It is promising to study the state of the submucous nerve plexus, as well as the cellular composition of the population of neurons of the enteric nervous system of domestic and wild poultry.

Keywords: birds; intestine; ontogenesis; histologic structure; enteric nervous system; myenteric nervous plexus; neurons.

\section{Introduction}

The enteric nervous system is the largest and most complex autonomous part of the peripheral nervous system, which together with the enteroendocrine and immune systems and when exposed to the microbiome under the control of the central nervous system regulates the vital functions of the digestive tract, including digestive, immune, hormonal and metabolic functions (Kulkarni et al., 2018; Pawolski \& Schmidt, 2020; Spencer \& Hu, 2020). The stomach and gut are organs that have evolved with their own independent nervous system, known as the gut nervous system. Innervation allows the organs of the intestinal tract to respond to various stimuli by regulating motility and secretion, as well as influencing the physiology, behaviour, and immunity of the whole organism (Ameku et al., 2020; Logvinova et al., 2020).

Neurocytes of the enteric nervous system are located mainly in the form of small clusters - ganglia, which maintain neuronal continuity with each other, forming two separate ganglion plexuses - the submucosa and the muscular membrane (myenteric, plexus Auerbachi). In the plexuses, the ganglia are interconnected by inter-nodal strands that carry axons over a considerable distance. In addition, isolated neurons are widespread in the gut wall (Aisa et al., 1990; Ameku et al., 2020).

During embryogenesis, the gut nervous system is formed from the cells of the vagus nerve crest, which emerge from the tail of the hindbrain, enter the anterior intestine, and inhabit the gastrointestinal tract (Freem et al., 2012; Ling \& Sauka-Spengler, 2019). The development of the enteric nervous system is controlled by the interaction of neural crest cell factors and signals from the intestinal mesenchyme (Burns \& Thapar, 2006). There is a significant effect of the gut microbiome on the processes of neurogenesis of the enteric nervous system (Popov et al., 2020). The process of its formation is a careful balancing of migration, proliferation and differentiation of both nerve cells and neuroglia (Nagy \& Goldstein, 2017). In such clusters, heparan sulfate, collagen XVIII and Agrin were found, which are important regulators of the development of cells derived from the neural crest (Nagy \& Goldstein, 2018). The intensive development of neurons in the gut of duck embryos is evidenced by the presence of arte$\mathrm{min}$ in its wall, which belongs to the family of neurotrophic factors neces- 
sary for the development of elements of nervous tissue (Maruccio et al., 2008). The general pattern of the enteric nervous system in the postnatal period of ontogenesis is a decrease in the number of its structural elements with age. During the normal life span of an individual, the population of gut neurons decreases, which is well documented in the scientific literature (Santer \& Baker, 1988; de Souza et al., 1993; Phillips et al., 2006; Yu et al., 2016). The death of neurons occurs in proportion to the decrease in neuroglial cells, which indicates their interdependence (Ippolito et al., 2009). This loss is one of the possible mechanisms of the dysfunction of the gastrointestinal tract observed in the elderly (Phillips et al., 2004). Such a decrease can contribute to a change in the functional characteristics of the organs of the digestive tube, slow down the processes of digestion and absorption of nutrients, thereby limiting the body in them (Amaral, 2010). The number of neurons in the gut decreases due to the action of mycotoxins (Gonkowski, 2020), Salmonella (Amaral et al., 2010). In this regard, it is increasingly important to assess the damage and degeneration of the enteric nervous system, to analyze the state of its ganglions and neurons (Ippolito et al., 2009), and for the treatment of neuronal deficiency that cause gut neuropathies, it is proposed to use stem cells (Zhang et al., 2019). Notably, the enteric nervous system has significant structural features in animals of different classes, even in different species of the same class that differ in size (Timmermans et al., 2001).

The features of the enteric nervous system of poultry remain an insufficiently studied section of comparative morphology. It is important to clarify the features of the morphofunctional organization of the nerve plexuses of the gut of domestic ducks, as well as other bird species. The aim of the study was to determine the topography and the main morphometric parameters of the ganglion of the myenteric plexus of the gut of domestic ducks during the first year of the postnatal period of ontogenesis.

\section{Materials and methods}

Ducks were kept and handled with in accordance with the European Convention for the Protection of Vertebrate Animals Used for Scientific Purposes (Strasbourg, 1986). The research protocol was approved by the Kharkiv State Zooveterinary Academy Commission on Bioethics. The experimental animals were taken out by a gradual overdose of ether for anesthesia. Material for research was taken from nine age groups of domestic duck (Anas platyrhynchos domesticus) of black white-breasted breed aged 1, 3, 7, 14, 21, 30, 60, 180 and 365 days, kept on deep litter at the Kharkiv State Zooveterinary Academy poultry house. During the observation period, the birds were clinically healthy, received standard complete feed, had free access to water. Prophylactic vaccinations and antiparasitic treatments were not carried out for ducks.

For histological studies, pieces of the middle section of the five intestines - duodenum, jejunum, ileum, caecum and rectum, were taken from five ducks of each age, which were fixed in a $10 \%$ solution of neutral formalin and embedded in paraffin. For the preparation of histological preparations, histological specimens with a thickness of 5-7 $\mu \mathrm{m}$ were stained with hematoxylin and eosin, azure II - eosin, Mallory staining. Determination of the morphometric parameters of the plexus microstructures was carried out on transverse sections of the intestine using a spectacle mesh and the Image Tools 3.6 software. The following indices of the nerve nodes of the plexus of the muscular membrane were determined: the total number on the section of the intestine, the average size of the ganglion, the number of neurons on the section of the ganglion, as well as the density of neurons (the number of neurons in the area of $1 \mu \mathrm{m}^{2}$ of the ganglion). The density of nerve cells in the plexus nodes was determined by dividing their number in a node by its area. The cross-sectional area of the nerve nodes, which were predominantly elliptical, was calculated by the formula $\mathrm{S}=\pi \mathrm{R}_{1} \mathrm{R}_{2}$. For the purpose of generalizing morphometric assessment of microscopic indicators of the morphofunctional state of the nerve nodes of the myenteric plexus of each intestine in ducks of 1-365 days of age, two parameters were determined: the average age index of the intestine and the average age index of the gut. The average age indicator of a certain structure of each intestine was determined as the arithmetic measure of its 9 age indicators. The average age index of a certain gut structure was determined as the arithmetic mean of the average age index of the structure of all five intestines. The average age index of a certain structure of each intestine was compared with the average age index of such a whole gut, which was defined as the relative average age index (\%).

The obtained data was analyzed in Biostat LE 7.3 (AnalystSoft Inc., Russia, 2020) software. The data is presented in the tables as $\mathrm{x} \pm$ standard deviation. Differences between the values in different age groups were determined using the Tukey test, where the differences were considered reliable at $\mathrm{P}<0.05$ (with taking into account Bonferroni correction).

\section{Results}

On histological preparations from a cross section of the intestinal wall of ducks of different ages, the nerve plexus of the muscular membrane (plexus myentericus s. Auerbachi) appears in the outer-longitudinal layer of the muscular membrane. Such plexuses are represented by clusters of neuronal bodies - nerve nodes (ganglia) and bundles of nerve fibers that connect. The nerve nodes of the plexus of the muscular membrane are clearly visible, have a predominantly elliptical shape, located in the outer layer of the muscular membrane between bundles of smooth muscle cells (Fig. 1). The nerve tissue of such ganglia is separated from the cells of smooth muscle tissue by a very thin capsule of fibers of fibrous loose connective tissue. Unlike nerve cords, which consist only of bundles of nerve fibers (Fig. 2), the nodes contain several bodies of multipolar nerve cells (Fig. 3).

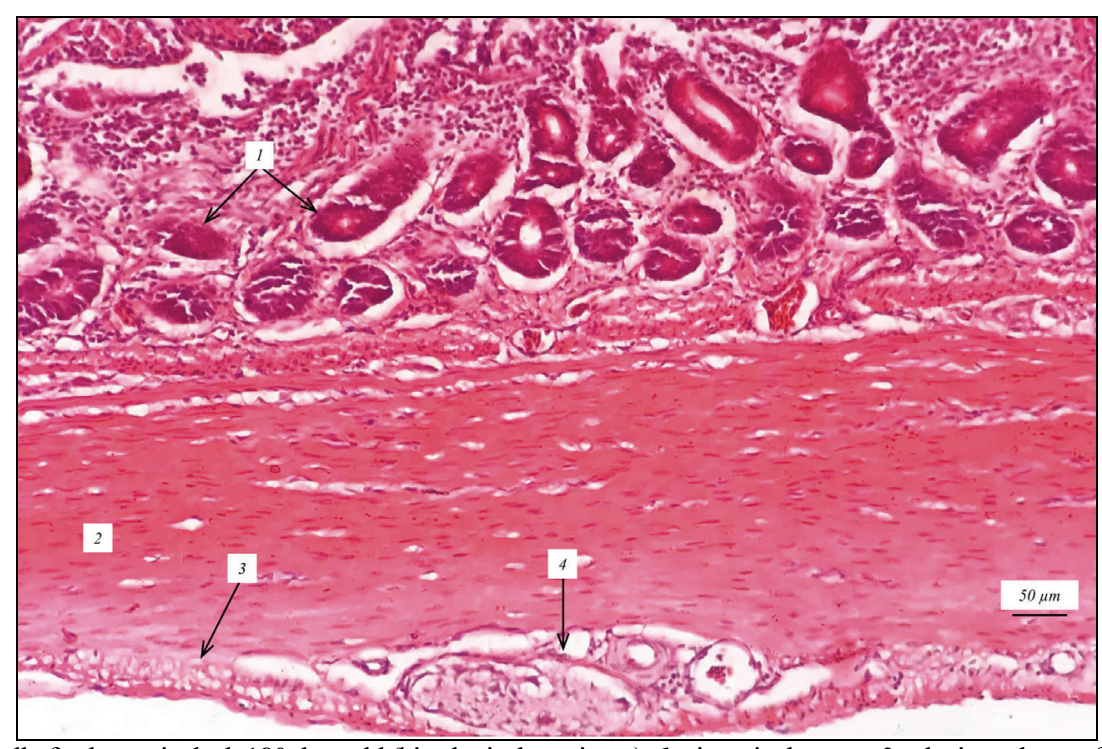

Fig. 1. Small intestine wall of a domestic duck 180 days old (histological specimen): 1 - intestinal crypts; 2 - the inner layer of the muscular membrane, 3 - the outer layer of the muscular membrane; 4 - ganglion of the nerve plexus of the muscular membrane; hematoxylin and eosin staining 


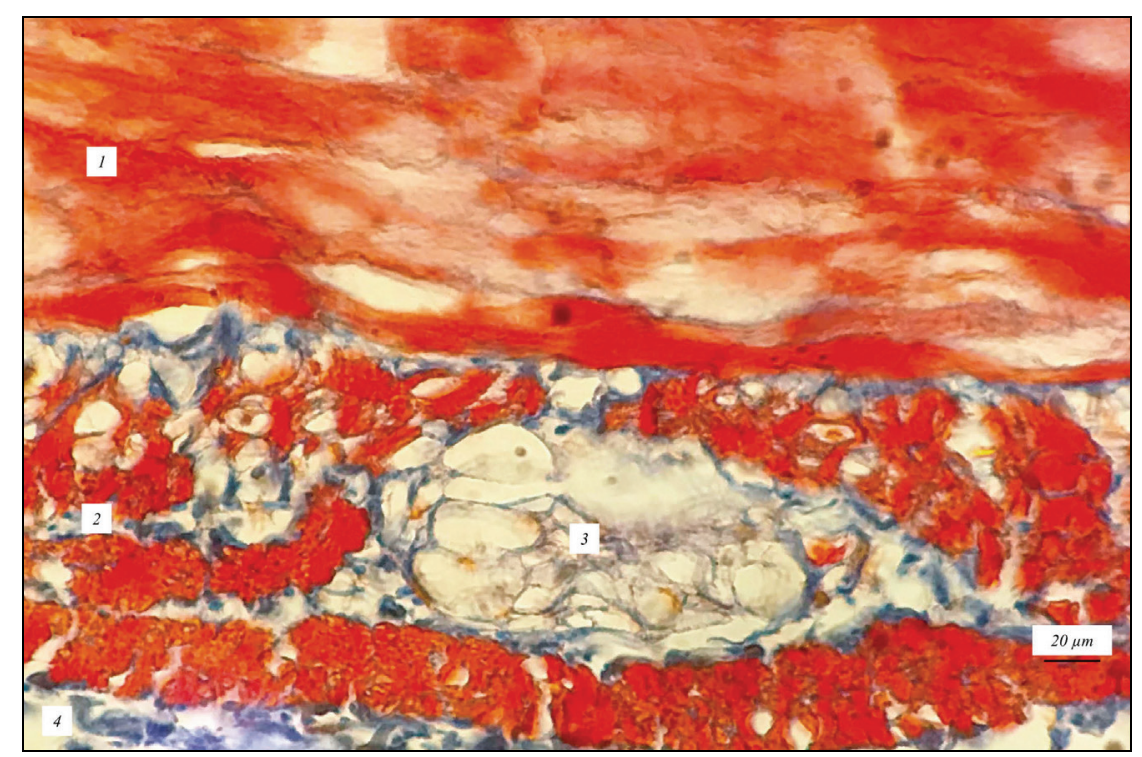

Fig. 2. The rectal wall of a 60-day-old domestic duck (histological specimen): 1 -the inner layer of the muscular membrane, 2 -the outer layer of the muscular membrane; 3 - nerve bundle of the plexus of the muscular membrane; 4 - serous membrane; Mallory staining

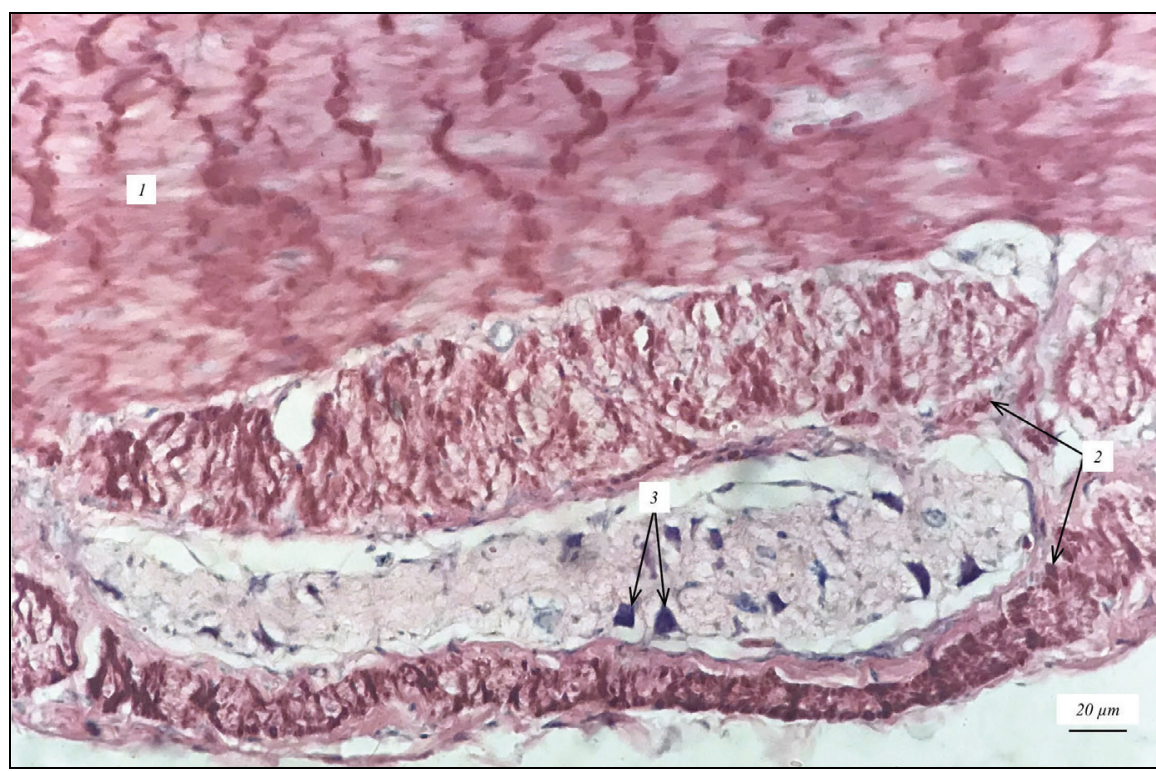

Fig. 3. The rectal wall of a 365-day-old domestic duck (histological specimen): 1 -the inner layer of the muscular membrane, 2 -the outer layer of the muscular membrane; 3 - neurocytes of the ganglion of the nerve plexus of the muscular membrane; staining azure II - eosin

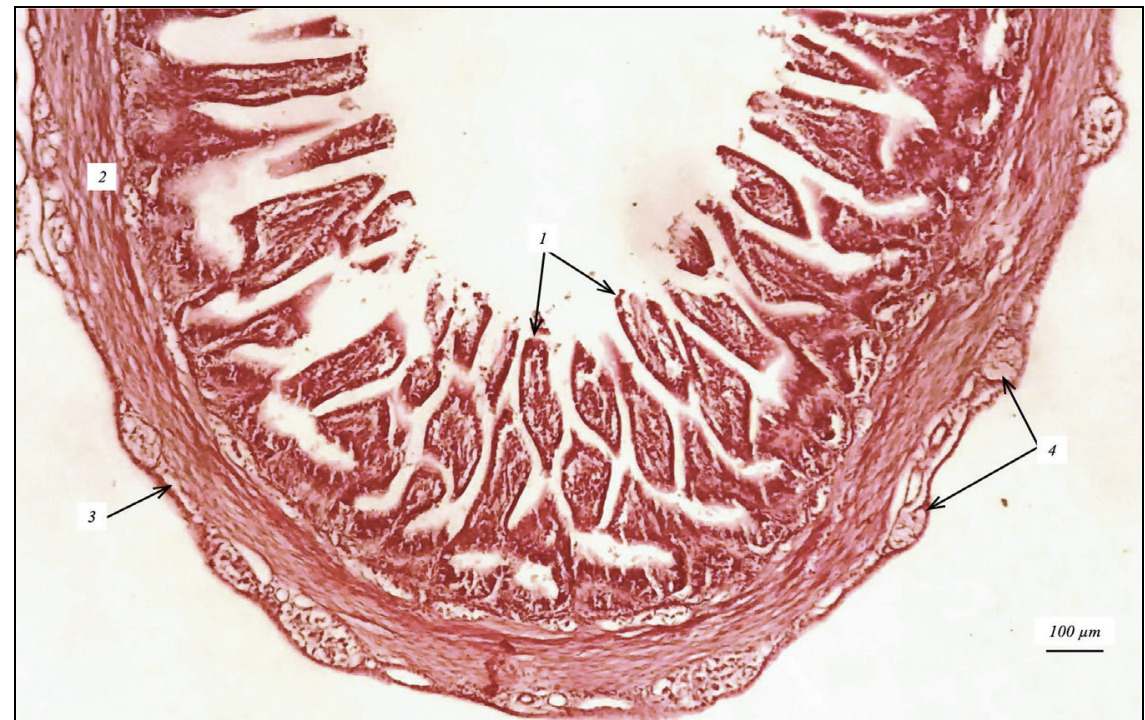

Fig. 4. The wall of the ileum of a 7-day-old domestic duck (histological specimen): 1 -intestinal villi; 2 - the inner layer of the muscular membrane, 3 - the outer layer of the muscular membrane; 4 - ganglia of the plexus of the muscular membrane; hematoxylin and eosin 
Considering the size of the nerve nodes and the thickness of the muscular membrane, the following structural feature of the myenteric ganglia in ducks of different ages should be noted. While the myenteric ganglia in ducks of a lesser and older age were approximately the same size, and at the same time the muscular membrane was of a much smaller thickness, the intestinal ganglia of ducks 1-7 days old are more clearly visible on histological slides (Fig. 4).

The total number of ganglia of the nerve plexus of the muscular membrane on a section of the gut wall of ducks during 1-365 days of age at different times differed with varying degrees of reliability in relation to such a young age (Table 1). So, this indicator was significantly lower in the duodenum at 21 and 60 days of age, in the jejunum - lower at 60 days of age and greater at 21 and 365 days of age, in the ileum - greater at the 7 th day of age, in the cecum - lower at 3 days of age, in the rectum lower at 14,30 and 60 days of age.

\section{Table 1}

Number of ganglia of the nerve plexus of the muscular membrane in the gut wall of ducks $1-365$ days of age $(x \pm S D, n=5)$

\begin{tabular}{cccccc}
\hline \multirow{2}{*}{$\begin{array}{c}\text { Age, } \\
\text { days }\end{array}$} & \multicolumn{5}{c}{ Intestine } \\
\cline { 2 - 6 } & duodenum & jejunum & ileum & cecum & rectum \\
\hline 1 & $15.2 \pm 4.50^{\mathrm{ab}}$ & $13.0 \pm 1.48^{\mathrm{bc}}$ & $12.7 \pm 1.74^{\mathrm{b}}$ & $10.6 \pm 1.10^{\mathrm{a}}$ & $13.5 \pm 1.59^{\mathrm{a}}$ \\
3 & $14.3 \pm 1.97^{\mathrm{ab}}$ & $12.7 \pm 1.21^{\mathrm{bc}}$ & $11.5 \pm 0.89^{\mathrm{b}}$ & $9.1 \pm 0.49^{\mathrm{ab}}$ & $12.5 \pm 1.43^{\mathrm{ab}}$ \\
7 & $15.3 \pm 1.39^{\mathrm{a}}$ & $14.5 \pm 1.48^{\mathrm{b}}$ & $15.4 \pm 1.77^{\mathrm{ab}}$ & $8.5 \pm 0.92^{\mathrm{b}}$ & $12.3 \pm 1.14^{\mathrm{ab}}$ \\
14 & $12.6 \pm 1.03^{\mathrm{b}}$ & $13.1 \pm 0.54^{\mathrm{bc}}$ & $13.3 \pm 1.27^{\mathrm{b}}$ & $7.4 \pm 1.36^{\mathrm{bc}}$ & $11.0 \pm 0.54^{\mathrm{b}}$ \\
21 & $10.5 \pm 0.74^{\mathrm{bc}}$ & $16.2 \pm 1.50^{\mathrm{a}}$ & $14.4 \pm 1.48^{\mathrm{ab}}$ & $8.4 \pm 0.96^{\mathrm{bc}}$ & $12.7 \pm 0.92^{\mathrm{ab}}$ \\
30 & $12.3 \pm 0.69^{\mathrm{bc}}$ & $15.0 \pm 1.48^{\mathrm{ab}}$ & $16.1 \pm 1.41^{\mathrm{ab}}$ & $7.7 \pm 1.01^{\mathrm{bc}}$ & $10.6 \pm 0.89^{\mathrm{bc}}$ \\
60 & $9.7 \pm 1.03^{\mathrm{c}}$ & $12.5 \pm 1.14^{\mathrm{bc}}$ & $16.4 \pm 1.21^{\mathrm{ab}}$ & $7.2 \pm 1.14^{\mathrm{bc}}$ & $8.9 \pm 0.36^{\mathrm{c}}$ \\
180 & $10.2 \pm 1.27^{\mathrm{bc}}$ & $11.6 \pm 0.94^{\mathrm{c}}$ & $16.3 \pm 1.07^{\mathrm{ab}}$ & $6.4 \pm 0.63^{\mathrm{c}}$ & $9.8 \pm 1.25^{\mathrm{bc}}$ \\
365 & $10.7 \pm 1.72^{\mathrm{bc}}$ & $13.0 \pm 0.58^{\mathrm{bc}}$ & $17.1 \pm 0.96^{\mathrm{a}}$ & $6.5 \pm 1.05^{\mathrm{c}}$ & $11.4 \pm 1.19^{\mathrm{ab}}$ \\
\hline
\end{tabular}

Note: different letters indicate the values significantly differing one from another within a column of Table 1 on the results of comparison using the Tukey test $(\mathrm{P}<$ 0.05) with Bonferroni correction.

The average age index of the number of plexus ganglia of the muscular membrane of the ducks gut was $12.0 \pm 2.57$. Considering the average age indicator of the number of ganglia in each intestine (Table 2) and the average age indicator of the number of intestinal ganglia, the relative average age indicator of the number of ganglia of the duodenum, jejunum, ileum, cecum and rectum was $102.5 \%$, respectively; $112.5 \%, 123.3 \%$, $66.7 \%$ and $95.0 \%$. That is, the cecum the lowest number of ganglia contained, and the largest - the ileum.

\section{Table 2}

Average age indices of the ganglia of the nerve plexus of the muscular membrane of the gut of ducks $1-365$ days of age $(x \pm S D, n=5)$

\begin{tabular}{lccccc}
\hline \multirow{1}{*}{$\begin{array}{c}\text { Age, } \\
\text { days }\end{array}$} & \multicolumn{5}{c}{ Intestine } \\
\cline { 2 - 6 } & duodenum & jejunum & ileum & cecum & rectum \\
\hline Number of ganglia on a & 12.3 & 13.5 & 14.8 & 8.0 & 11.4 \\
section of the intestinal wall & $\pm 1.63^{\mathrm{b}}$ & $\pm 1.07^{\mathrm{ab}}$ & $\pm 1.43^{\mathrm{a}}$ & $\pm 1.01^{\mathrm{c}}$ & $\pm 1.12^{\mathrm{bc}}$ \\
& 2900 & 2142 & 2819 & 2490 & 2608 \\
Ganglion square, $\mu \mathrm{m}^{2}$ & $\pm 276^{\mathrm{a}}$ & $\pm 263^{\mathrm{b}}$ & $\pm 333^{\mathrm{ab}}$ & $\pm 239^{\mathrm{ab}}$ & $\pm 234^{\mathrm{ab}}$ \\
& 7.0 & 7.0 & 6.3 & 5.5 & 7.6 \\
Number of neurons per & $\pm 1.36^{\mathrm{ab}}$ & $\pm 0.56^{\mathrm{ab}}$ & $\pm 0.58^{\mathrm{b}}$ & $\pm 0.58^{\mathrm{b}}$ & $\pm 0.80^{\mathrm{a}}$ \\
section of one ganglion & 2415 & 3440 & 2666 & 2242 & 2912 \\
The density of neurons in & $\pm 520^{\mathrm{b}}$ & $\pm 457^{\mathrm{a}}$ & $\pm 337^{\mathrm{b}}$ & $\pm 354^{\mathrm{b}}$ & $\pm 388^{\mathrm{ab}}$ \\
the ganglion section & & & &
\end{tabular}

Note: different letters indicate the values significantly differing one from another within a line of the Table 5 on the results of comparison using the Tukey test $(\mathrm{P}<$ 0.05) with Bonferroni correction.

Compared with ducks of one day of age, at 365 days of age, the area of the ganglion of the plexus of the muscular membrane of the gut is larger (Table 3). Notably, this indicator reached the greatest value at different age periods: at 30 days of age in the ileum and cecum, at 180 days of age - in the rectum and at 365 days of age - in the duodenum. During the first year of the postnatal period of ontogenesis, the area of the myenteric ganglion in the wall of various intestines of ducks changed with age, increasing or decreasing relative to the value of the previous age. Significant changes in the average ganglion area of ducks of a relatively younger age were established at different age periods: in the duodenum it was less at 60 days of age and more at 3 days of age, in the jejunum - smaller at 14 and 365 days of age and greater at 3 and 180 days of age, in the ileum - lesser at 60 days of age and larger at 21 and 30 days of age, in the cecum - less at 180 days of age and greater at 3 and 30 days daily, in the rectum - greater at 180 days of age.

\section{Table 3}

The area of the nerve plexus node of the muscular membrane of the gut of ducks 1-365 days of age $\left(\mu \mathrm{m}^{2}, \mathrm{x} \pm \mathrm{SD}, \mathrm{n}=5\right)$

\begin{tabular}{cccccc}
\hline \multirow{2}{*}{$\begin{array}{c}\text { Age, } \\
\text { days }\end{array}$} & \multicolumn{5}{c}{ Intestine } \\
\cline { 2 - 6 } & duodenum & jejunum $^{\mathrm{c}}$ & ileum & cecum & rectum \\
\hline 1 & $2391 \pm 200^{\mathrm{b}}$ & $1704 \pm 360^{\mathrm{c}}$ & $2507 \pm 344^{\mathrm{b}}$ & $1913 \pm 247^{\mathrm{b}}$ & $2867 \pm 294^{\mathrm{ab}}$ \\
3 & $3342 \pm 360^{\mathrm{ab}}$ & $2467 \pm 312^{\mathrm{ab}}$ & $2524 \pm 204^{\mathrm{b}}$ & $2370 \pm 290^{\mathrm{ab}}$ & $3004 \pm 203^{\mathrm{ab}}$ \\
7 & $3162 \pm 424^{\mathrm{ab}}$ & $2528 \pm 404^{\mathrm{ab}}$ & $2467 \pm 341^{\mathrm{b}}$ & $2706 \pm 268^{\mathrm{ab}}$ & $2676 \pm 403^{\mathrm{ab}}$ \\
14 & $2880 \pm 314^{\mathrm{ab}}$ & $1883 \pm 219^{\mathrm{bc}}$ & $2322 \pm 266^{\mathrm{b}}$ & $2522 \pm 200^{\mathrm{ab}}$ & $2196 \pm 358^{\mathrm{b}}$ \\
21 & $3380 \pm 403^{\mathrm{a}}$ & $1813 \pm 290^{\mathrm{c}}$ & $3134 \pm 361^{\mathrm{ab}}$ & $2443 \pm 218^{\mathrm{ab}}$ & $2431 \pm 383^{\mathrm{ab}}$ \\
30 & $2984 \pm 307^{\mathrm{ab}}$ & $2004 \pm 198^{\mathrm{b}}$ & $3732 \pm 179^{\mathrm{a}}$ & $2908 \pm 363^{\mathrm{a}}$ & $2618 \pm 274^{\mathrm{ab}}$ \\
60 & $2353 \pm 224^{\mathrm{b}}$ & $2217 \pm 223^{\mathrm{ab}}$ & $3135 \pm 381^{\mathrm{ab}}$ & $2744 \pm 217^{\mathrm{ab}}$ & $2372 \pm 196^{\mathrm{b}}$ \\
180 & $2710 \pm 363^{\mathrm{ab}}$ & $2703 \pm 344^{\mathrm{a}}$ & $2812 \pm 312^{\mathrm{b}}$ & $2108 \pm 251^{\mathrm{b}}$ & $3127 \pm 272^{\mathrm{a}}$ \\
365 & $2893 \pm 420^{\mathrm{ab}}$ & $1958 \pm 219^{\mathrm{bc}}$ & $2738 \pm 309^{\mathrm{b}}$ & $2694 \pm 538^{\mathrm{ab}}$ & $2909 \pm 311^{\mathrm{ab}}$ \\
\hline
\end{tabular}

Note: see Table 1 .

The average age index of the ganglion area of the muscular membrane of the ducks' gut was $2.592 \pm 300 \mu \mathrm{m}^{2}$. Taking into account the average age index of the area of the ganglion of each intestine (Table 2) and the average age index of the area of the gut ganglion, the relative average age index of the area of the ganglion of the muscular membrane of the duodenum, jejunum, ileum, cecum and rectum, respectively, was $111.9 \%, 82.6 \%, 108.8 \%, 96.1 \%$ and $100.6 \%$. Thus, the lowest average value of this indicator was found in the jejunum, which was $2142 \pm$ $263 \mu \mathrm{m}^{2}$, and the highest -in the duodenum, which was $2900 \pm 276 \mu \mathrm{m}^{2}$.

The general regularity of the cellular composition of ganglia (Fig. 4) was a decrease in the number of neurons in them with age. So, in comparison with one day old ducks, at 365 days of age their number was less (Table 4).

\section{Table 4}

The number of neurons in the nodes of the nerve plexus of the muscular membrane of the gut of ducks $1-365$ days of age $(x \pm S D, n=5)$

\begin{tabular}{|c|c|c|c|c|c|}
\hline \multirow{2}{*}{$\begin{array}{l}\text { Age, } \\
\text { days }\end{array}$} & \multicolumn{5}{|c|}{ Intestine } \\
\hline & duodenum & jejunum & ileum & cecum & rectum \\
\hline 1 & $8.8 \pm 0.83^{b}$ & $7.9 \pm 0.76^{\mathrm{a}}$ & $7.6 \pm 0.67^{\mathrm{a}}$ & $5.8 \pm 0.67^{\mathrm{ab}}$ & $8.9 \pm 0.77^{\mathrm{a}}$ \\
\hline 3 & $10.6 \pm 0.58^{\mathrm{a}}$ & $7.3 \pm 0.65^{\mathrm{ab}}$ & $7.0 \pm 0.67^{\mathrm{ab}}$ & $6.4 \pm 0.89^{\mathrm{a}}$ & $8.4 \pm 0.89^{\mathrm{ab}}$ \\
\hline 7 & $6.6 \pm 0.78^{\mathrm{od}}$ & $6.8 \pm 0.67^{\mathrm{ab}}$ & $5.3 \pm 0.74^{c}$ & $5.7 \pm 0.80^{\mathrm{ab}}$ & $8.3 \pm 0.65^{\mathrm{ab}}$ \\
\hline 14 & $7.2 \pm 0.92^{\mathrm{od}}$ & $7.3 \pm 0.60^{\mathrm{ab}}$ & $6.1 \pm 0.67^{b}$ & $5.1 \pm 0.60^{\mathrm{ab}}$ & $8.5 \pm 0.72^{\mathrm{ab}}$ \\
\hline 21 & $4.8 \pm$ & $6.6 \pm 0.54^{b}$ & $5.5 \pm 0.67^{b c}$ & $5.3 \pm 0.47^{\mathrm{ab}}$ & $7.6 \pm 0.51^{\mathrm{ab}}$ \\
\hline 30 & $5.0 \pm 0.56^{\mathrm{d}}$ & $5.3 \pm 0.67^{c}$ & $7.0 \pm 0.63^{\mathrm{ab}}$ & $4.5 \pm 0.56^{b}$ & $6.5 \pm 0.54^{b c}$ \\
\hline 60 & $5.7 \pm 0$ & $7.0 \pm 0.63^{\mathrm{ab}}$ & $5.5 \pm 0.45^{b c}$ & $5.0 \pm 0.45^{\mathrm{b}}$ & $5.5 \pm 0.60^{c}$ \\
\hline 180 & $6.9 \pm 0.67^{\mathrm{dd}}$ & $7.4 \pm 0.89^{\mathrm{ab}}$ & $6.2 \pm 0.69^{\mathrm{ab}}$ & $5.7 \pm 0.44^{\mathrm{ab}}$ & $7.2 \pm 0.67^{b}$ \\
\hline 365 & $7.3 \pm 0.74^{c}$ & $7.5 \pm 0.74^{\mathrm{ab}}$ & $6.1 \pm 0.60^{b}$ & $5.1 \pm 0.72^{\mathrm{ab}}$ & $7.6 \pm 0.96^{\mathrm{ab}}$ \\
\hline
\end{tabular}

Note: see Table 1.

At the same time, from 1-365 days of age, it increased or decreased at a relatively younger age. So, in comparison with ducks of a younger age, in the duodenum their number was significantly less at 7 and 21 days of age and more at 3 and 180 days of age, in the jejunum - lower at 30 days of age and greater at 60 days of age, in the ileum - lower at 7 and 60 days of age, in the cecum - lower at 60 days of age, in the rectum - lower at 21 and 30 days of age and higher at 180 days.

The average age index of the number of neurons in one gut myenteric ganglion was $6.7 \pm 0.80$. Considering the average age index of the number of neurons in the ganglion of each intestine (Table 2) and the average age index of the gut ganglion area, the relative average age index of the number of neurons in the ganglion of different intestines differed significantly and in the duodenum, jejunum, ileum, cecum and rectum was $104.5 \%$, respectively; $104.5 \%, 94.0 \%, 82.1 \%$ and $113.4 \%$. That is, the lowest number of neurons in the myenteric ganglion was contained in the wall of the cecum and ileum, which was $5.5 \pm 0.58$ and $6.3 \pm 0.58$, respectively, and the largest was in the rectum, which was $7.6 \pm 0.80$.

The general pattern of dynamics of nerve cell density in the myenteric ganglion of the gut of ducks was a decrease with age (Table 5). Compared with one-day-old ducks, at the age of 365 days their number was lower. The average age indicator of neuron density in the nerve plexus node of 
the muscular membrane of the gut of ducks was $2735 \pm 469$ cells per $1 \mu \mathrm{m}^{2}$ of ganglion area.

\section{Table 5}

The density of neurons in the nerve plexus node of the muscular membrane of the gut of ducks 1-365-day-old $(x \pm S D, n=5)$

\begin{tabular}{cccccc}
\hline \multirow{2}{*}{$\begin{array}{c}\text { Age, } \\
\text { day }\end{array}$} & \multicolumn{5}{c}{ Type of gut } \\
\cline { 2 - 6 } & duodenum & jejunum $^{\mathrm{i}}$ & ileum & cecum & rectum \\
\hline 1 & $3682 \pm 345^{\mathrm{a}}$ & $4606 \pm 407^{\mathrm{a}}$ & $2981 \pm 386^{\mathrm{a}}$ & $2990 \pm 322^{\mathrm{a}}$ & $3112 \pm 339^{\mathrm{bc}}$ \\
3 & $3172 \pm 234^{\mathrm{ab}}$ & $3083 \pm 305^{\mathrm{c}}$ & $2804 \pm 333^{\mathrm{ab}}$ & $2712 \pm 308^{\mathrm{ab}}$ & $2809 \pm 333^{\mathrm{bc}}$ \\
7 & $2063 \pm 203^{\mathrm{cd}}$ & $2636 \pm 237^{\mathrm{c}}$ & $2137 \pm 291^{\mathrm{b}}$ & $2044 \pm 177^{\mathrm{bc}}$ & $3097 \pm 338^{\mathrm{bc}}$ \\
14 & $2502 \pm 225^{\mathrm{bc}}$ & $3789 \pm 324^{\mathrm{b}}$ & $2641 \pm 262^{\mathrm{ab}}$ & $2024 \pm 221^{\mathrm{bc}}$ & $4001 \pm 353^{\mathrm{a}}$ \\
21 & $1412 \pm 172^{\mathrm{d}}$ & $3687 \pm 240^{\mathrm{bc}}$ & $1752 \pm 242^{\mathrm{b}}$ & $2172 \pm 230^{\mathrm{bc}}$ & $3235 \pm 205^{\mathrm{b}}$ \\
30 & $1678 \pm 200^{\mathrm{d}}$ & $2663 \pm 263^{\mathrm{c}}$ & $1872 \pm 185^{\mathrm{b}}$ & $1546 \pm 214^{\mathrm{c}}$ & $2605 \pm 336^{\mathrm{bc}}$ \\
60 & $2311 \pm 227^{\mathrm{c}}$ & $3319 \pm 255^{\mathrm{bc}}$ & $1763 \pm 119^{\mathrm{b}}$ & $1838 \pm 205^{\mathrm{bc}}$ & $2511 \pm 255^{\mathrm{c}}$ \\
180 & $2509 \pm 217^{\mathrm{b}}$ & $3458 \pm 313^{\mathrm{bc}}$ & $2222 \pm 302^{\mathrm{b}}$ & $2664 \pm 262^{\mathrm{ab}}$ & $2261 \pm 235^{\mathrm{c}}$ \\
365 & $2405 \pm 476^{\mathrm{bc}}$ & $3713 \pm 334^{\mathrm{bc}}$ & $2226 \pm 254^{\mathrm{b}}$ & $2186 \pm 235^{\mathrm{b}}$ & $2577 \pm 293^{\mathrm{c}}$ \\
\hline
\end{tabular}

Note: see Table 1.

Given the average age of neuronal density in the ganglion of each intestine (Table 2) and the average age of neuronal density in the gut ganglion, the relative average age of neuronal density in different intestines differed in the duodenum, jejunum, ileum, cecum and rectum, respectively $125.8 \%, 97.5 \%, 82.0 \%$ and $106.5 \%$. That is, the lowest density of neurons per $1 \mu \mathrm{m}^{2}$ of ganglion of the muscular plexus was in the cecum and duodenum and was $2242 \pm 354$ and $2415 \pm 520$, respectively, and the highest - in the jejunum and was $3439 \pm 457$ per $1 \mu \mathrm{m}^{2}$.

\section{Discussion}

In mammals the myenteric nerve plexus is known to be located between the inner and outer layers of the gut mucosa (Faller et al., 2004; Mandić et al., 2016; Ameku et al., 2020). The location of the ganglion and bundles of the myenteric nerve plexus in the outer layer of the muscular membrane of the gut of ducks is consistent with the relevant information regarding their topography in chickens and geese (Kuder et al., 2003; Kushch et al., 2016). At the same time, in pigeons it is localized between the layers of the muscular membrane (Kuder et al., 2003). In the wall of the glandular part of the stomach of ducks (Anas platyrhynchos) ganglia of the myenteric plexus were found between the layers of the muscular membrane (Mirabella et al., 2003), and in the wall of the muscular part of the stomach of chickens - directly under the serous membrane and in its circular layer (Gabella \& Halasy, 1987).

According to recent studies, the enteric nervous system is an extremely dynamic formation in which there is a constant death of some neurons and their continuous replacement with new ones (Kabouridis \& Pachnis, 2015; Ameku et al., 2020; Spencer \& Hu, 2020). Moreover, a significant number of neurons in the gut plexuses, which are detected in a state of apoptosis, indicates a high rate of their rotation and short life (Margolis et al., 2016). In the human small intestine, a significantly large $(\sim 31 \%)$ number of caspase-3-labeled neurons, a marker of apoptosis, were lost within 7 days, meaning 4-5\% loss per day, or 1 neuron per 1 ganglion per day (Kulkarni et al., 2017).

These data contradict the existing dogma of the lack of neurogenesis in the gut of the adult organism, i.e, of static, unchanged composition of its nerve elements: plexuses, ganglia, nerve and neuroglial cells (Joseph et al., 2011). Large scale apoptosis of neurocytes in the ganglia, a large number of macrophages associated with them, indicating phagocytosis of dead cells, and the detection of cells - probable precursors of neurons located in the ganglion and expressing nestin - a protein, testifies to the new theory involved in neurogenesis (Kulkarni et al., 2017). Brain-specific protein oligophrenin-1, which is involved in the regulation of changes in the shape and growth of axons and dendrites, which is central to the mechanisms of plasticity, learning and memory, has been found in neurons of the enteric nervous system (Xiao et al., 2003). This situation creates a completely new paradigm of the enteric nervous system, which is important not only in general biological but also clinical significance. Our data on the change in morphometric parameters of the ganglia of the nerve plexus of the muscular membrane of the gut of ducks 1-365 days of age are fully con- sistent with the idea of constant and rapid replacement of neurons of the enteric nervous system in the postnatal period of ontogeny.

A number of researchers report changes in the number of structural elements of the enteric nervous system of humans and animals both with age and in different intestines. Thus, the density of ganglia and neurons in the gut of chickens decreases, and the average number of neurons in the myenteric ganglia increases with different dynamics along its longitudinal axis from 19 days of incubation to 7 days after hatching (Román et al., 2001) data from Yang et al. (2013). Moreover, in all age groups of birds, the largest number was in the rectum, followed by the ileum, duodenum, jejunum and cecum. In the myenteric plexus, the number of neurons in the gut of older rats was $40 \%$ lower than in young rats, and $38 \%$ less in older guinea pigs in the submucosal ganglia (Santer \& Baker, 1988; Zanesco \& de Souza, 2011). A marked decrease in the density of neurons in the myental plexus of the human gut during the first years of life is reported by Wester et al. (1999), indicating the continued development of the enteric nervous system.

According to the results of our research, it was found that, despite a significant increase with age in the diameter and thickness of the wall and, including the muscular membrane, of the gut of ducks, the total number of myenteric ganglia changed to a much lesser extent. It is worth noting the multidirectional nature of the change in this parameter: compared with one day old ducklings, in 365-day-old ducks the number of myenteric ganglia in the duodenum, cecum and rectum was smaller, in the ileum - larger, and jejunum - almost unchanged. Due to the determination of the average age index, it was found that in ducks 1-365 days of age, the smallest number of myenteric ganglia is contained in the cecum, the largest - in the rectum and ileum. During the first year of the postnatal period of duck ontogenesis, the area of the myenteric ganglion in different intestines changed with age, increasing or decreasing relative to the value of previous age. The general pattern of the dynamics of their size in different intestines was an increase with age of their average area. According to the results of determining the average age, the smallest area of the myenteric ganglion was in the large intestine, the largest - in the duodenum and ileum, which is consistent with information about the greater thickness of its elements in the duodenum compared to other parts of the gut of chicken and pigeon (Kuder et al., 2003).

According to the average age indicator, the smallest number of neurons was contained in the myenteric ganglia of the cecum and ileum, and the largest - the rectum. The general pattern of the dynamics of the number of neurons in the ganglia was their decrease with age. During 1-365 days of age, their number increased or decreased relative to a younger age. At the same time, the density of neurons in the ganglia was the lowest in the plexuses of the cecum and duodenum, and the highest - in the jejunum.

Probably, changes in the number and area of ganglia, the number and density of nerve cells of the myenteric plexus in the gut of ducks are an indicator of the plastic state of the enteric nervous system, its ability to respond dynamically to internal and external factors.

\section{Conclusions}

On histological slides from the cross section of the intestines of domestic ducks, the ganglia of the nerve plexus of the muscular membrane have an elliptical shape and are found in its outer layer. Despite a significant increase in the thickness of the gut wall and muscular membrane with age, the number of myenteric ganglia in different intestines during the first year of the postnatal period of ontogenesis changes to a lesser extent and in different directions. The general pattern of changes in the area of the myenteric ganglia in the gut of ducks from 1-365-days of age is an increase with age in their average size. With age, the density of neurons in the ganglia of the ducks' plexus gradually decreases. In order to assess the state of the enteric nervous system, it is advisable to study the features of its microscopic structure in other species of domestic and wild birds, and also under the influence of biotic and abiotic factors. Given the dynamic nature of changes in morphometric parameters of gut nerve ganglia during the first year of the postnatal period of ontogenesis, in order to objectively assess their size in different intestines, it was advisable to use such a parameter as the average age. 
Aisa, J., Parra, P., \& Azanza, M. J. (1990). Ultrastructural characteristics of anterior gut innervation of Gallus gallus. Histology and Histopathology, 5(3), 281-287.

Ali, H. A., \& McLelland, J. (1978). Avian enteric nerve plexuses. A histochemical study. Cell and Tissue Research, 189(3), 537-548.

Amaral, P. F. G. P., Santos, G. R., Urano, T. K., Diniz, K. da S., Gonçalves, T. dos S. A., Serenini, G. de F., Otutumi, L. K., \& Germano, R. de M. (2010). Salmonella heidelberg reduces nitrergic neurons in the myenteric plexus of the duodenum of broilers. African Journal of Microbiology Research, 11(33), 1315-1320.

Ameku, T., Beckwith, H., Blackie, L., \& Miguel-Aliaga, L. (2020). Food, microbes, sex and old age: On the plasticity of gastrointestinal innervation. Current Opinion in Neurobiology, 62, 83-91.

Bor-Seng-Shu, E., Chadi, G., Bor-Jiun-Shu, F., Ferraz-de-Carvalho, C. A., \& de-Souza, R. R. (1994). Myenteric neurons of the mouse small intestine. Morphometry and acetylcholinesterase activity. Brazilian Journal of Medical and Biological Research, $27(1), 101-108$.

Burns, A. J., \& Thapar, N. (2006). Advances in ontogeny of the enteric nervous system. Journal of Neurogastroenterology and Motility, 18(10), 876-887.

De Souza, R. R., Moratelli, H. B., Borges, N., \& Liberti, E. A. (1993). Age-induced nerve cell loss in the myenteric plexus of the small intestine in man. Gerontology, 39(4), 183-188.

Faller, A., Schuenke, M., \& Schuenke, G. M. (2004). The human body. Stuttgart, NewYork, Thieme.

Freem, L. J., Delalande, J. M., Campbell, A. M., Thapar, N., \& Burns, A. J. (2012) Lack of organ specific commitment of vagal neural crest cell derivatives as shown by back-transplantation of GFP chicken tissues. The International Journal of Developmental Biology, 56(4), 245-254.

Gabella, G., \& Halasy, K. (1987). On the nerve plexus of the chicken gizzard. Anatomy and Embryology, 177(2), 97-103.

Gonkowski, S., Gajęcka, M., \& Makowska, K. (2020). Mycotoxins and the enteric nervous system. Toxins, 12(461), 1-28

Ippolito, C., Segnani, C., De Giorgio, R., Blandizzi, C., Mattii, L., Castagna, M., Moscato, S., Dolfi, A.., \& Bernardini, N. (2009). Quantitative evaluation of myenteric ganglion cells in normal human left colon: Implications for histopathological analysis. Cell and Tissue Research, 336(2), 191-201.

Joseph, N. M., He, S., Quintana, E., Kim, Y., Núñez, G., \& Morrison, S. J. (2011). Enteric glia are multipotent in culture but primarily form glia in the adult rodent gut. The Journal of Clinical Investigation, 121(9), 3398-3411.

Kabouridis, P. S., \& Pachnis, V. (2015). Emerging roles of gut microbiota and the immune system in the development of the enteric nervous system. The Journal of Clinical Investigation, 125(3), 956-964.

Karaosmanoglu, T., Aygun, B., Wade, P. R., \& Gershon, M. D. (1996). Regional differences in the number of neurons in the myenteric plexus of the guinea pig small intestine and colon: An evaluation of markers used to count neurons. The Anatomical Record, 244(4), 470-480.

Kuder, T., Nowak, E., Szczurkowski, A., \& Kuchinka, J. (2003). The comparative analysis of the myenteric plexus in pigeon and hen. Comparative study. Anatomia, Histologia, Embryologia, 32(1), 1-5.

Kulkarni, S., Ganz, J., Bayrer, J., Becker, L., Bogunovic, M., \& Rao, M. (2018). Advances in enteric neurobiology: The "brain" in the gut in health and disease. Journal of Neuroscience, 38(44), 9346-9354.

Kulkarni, S., Micci, M.-A., Leser, J., Shin, C., Tang, S.-C., Fu, Y.-Y., Liu, L., Li, Q., Saha, M., Li, C., Enikolopov, G., Becker, L., Rakhilin, N., Anderson, M., Shen, X. Dong, X., Butte, M. J., Song, H., Southard-Smith, E. M., Kapur, R. P., Bogunovic, M., \& Pasricha, P. J. (2017). Neurogenesis and turnover of adult enteric neurons. Proceedings of the National Academy of Sciences, 114(18), 3709-3718.

Kushch, M. M., Kushch, L. L., Byrka, E. V., Byrka, V. V., \& Yaremchuk, O. S. (2019). Morphological features of the jejunum and ileum of the middle and heavy goose breeds. Ukrainian Journal of Ecology, 9(4), 690-694.

Ling, I. T. C., \& Sauka-Spengler, T. (2019). Early chromatin shaping predetermines multipotent vagal neural crest into neural, neuronal and mesenchymal lineages. Nature Cell Biology, 21(12), 1504-1517

Logvinova, V. V., Oliyar, A. V., \& Lieshchova, M. A. (2020). Formation of immune structures in small intestine of Muscovy ducks (Cairina moschata). Theoretical and Applied Veterinary Medicine, 8(1), 50-55.
Maifrino, L. B., Prates, J. C., De-Souza, R. R., \& Liberti, E. A. (1997). Morphometry and acetylcholinesterase activity of the myenteric plexus of the wild mouse $\mathrm{Ca}$ lomys callosus. Brazilian Journal of Medical and Biological Research, 30(5), $627-632$.

Mandić, P., Filipović, T., Gasić, M., Djukić-Macut, N., Filipović, M., \& Bogosavljević, I. (2016). Quantitative morphometric analysis of the myenteric nervous plexus ganglion structures along the human digestive tract. Vojnosanitetski Pregled, 73(6), 559-565.

Margolis, K. G., Gershon, M. D. \& Bogunovic, M. (2016). Cellular organization of neuroimmune interactions in the gastrointestinal tract. Trends in Immunology, $37(7), 487-501$.

Maruccio, L., Lucini, C., Russo, F., Antonucci, R., \& Castaldo, L. (2008). The development of avian enteric nervous system: Distribution of artemin immunoreactivity. Acta Histochemica, 110(2), 163-171.

Mirabella, N., Squillacioti, C., Genovese, A., Germano, G., \& Paino, G. (2003). Topography and neurochemistry of the enteric ganglion in the proventriculus of the duck (Anas platyrhynchos). Anatomy and Embryology, 207(2), 101-108.

Nagy, N., \& Goldstein, A. M. (2017). Enteric nervous system development: A cres cell's journey from neural tube to colon. Seminars in Cell and Developmental Biology, 66, 94-106.

Pawolski, V., \& Schmidt, M. H. H. (2020). Neuron - glia interaction in the developing and adult enteric nervous system. Cells, 10(1), 47

Phillips, R. J., Kieffer, E. J., \& Powley, T. L. (2004). Loss of glia and neurons in the myenteric plexus of the aged Fischer 344 rat. Anatomy and Embryology, 209(1), 19-30

Phillips, R. J., Rhodes, B. S., \& Powley, T. L. (2006). Effects of age on sympathetic innervation of the myenteric plexus and gastrointestinal smooth muscle of Fischer 344 rats. Anatomy and Embryology, 211(6), 673-683.

Popov, J., Bandura, J., Markovic, F., Borojevic, R., Anipindi, V. C., Pai, N. \& Ratcliffe, E. M. (2020). Influence of bacterial components on the developmental programming of enteric neurons. Physiological Reports, 8(21), el4611.

Román, V., Krecsmarik, M., Bagyánszki, M., \& Fekete, E. (2001). Evaluation of the total number of myenteric neurons in the developing chicken gut using cuprolinic blue histochemical staining and neurofilament immunocytochemistry. Histochemistry and Cell Biology, 116(3), 241-246.

Santer, R. M., \& Baker, D. M. (1988). Enteric neuron numbers and sizes in Auerbach's plexus in the small and large intestine of adult and aged rats. Journal of the Autonomic Nervous System, 25(1), 59-67.

Spencer, N. J., \& Hu, H. (2020). Enteric nervous system: Sensory transduction, neural circuits and gastrointestinal motility. Nature Reviews Gastroenterology and Hepatology, 17(6), 338-351.

Timmermans, J. P., Hens, J., \& Adriaensen, D. (2001). Outer submucous plexus: An intrinsic nerve network involved in both secretory and motility processes in the intestine of large mammals and humans. The Anatomical Record, 262(1), 71-78

Wester, T., O'Briain, D. S., \& Puri, P. (1999). Notable postnatal alterations in the myenteric plexus of normal human bowel. Gut, 44(5), 666-674

Xiao, J., Neylon, C. B., Hunne, B., \& Furness, J. B. (2003). Oligophrenin-1, a Rho GTPase-activating protein (RhoGAP) involved in X-linked mental retardation, is expressed in the enteric nervous system. The Anatomical Record, 273A(2), 671-676.

Yang, P., Gandahi, J. A., Zhang, Q., Zhang, L., Bian, X., Wu, L., Liu, Y., \& Chen, Q (2013). Quantitative changes of nitrergic neurons during postnatal development of chicken myenteric plexus. Journal of Zhejiang University - Science B, $14(10), 886-895$

Yu, Y., Daly, D. M., Adam, I. J., Kitsanta, P., Hill, C. J., Wild, J., Shorthouse, A., Grundy, D., \& Jiang, W. (2016). Interplay between mast cells, enterochromaffin cells, and sensory signaling in the aging human bowel. Journal of Neurogastroenterology and Motility, 28(10), 1465-1479.

Zanesco, M. C., \& de Souza, R. R. (2011). Morphoquantitative study of the submucous plexus (of Meissner) of the jejunum-ileum of young and old guinea pigs. Arquivos de Neuro-Psiquiatria, 69(1), 85-90.

Zhang, D., Rollo, B. N., Nagy, N., Stamp, L., \& Newgreen, D. F. (2019). The enteric neural crest progressively loses capacity to form enteric nervous system. Developmental Biology, 446(1), 34-42. 